\title{
Influence of Foundation Pit Excavation and Precipitation on Settlement of Surrounding Buildings
}

\author{
Hongming Wei $(\mathbb{D}$ \\ School of Civil Engineering and Environment, Hubei University of Technology, Wuhan 430068, Hubei, China \\ Correspondence should be addressed to Hongming Wei; 101810531@hbut.edu.cn
}

Received 17 December 2020; Revised 8 January 2021; Accepted 31 January 2021; Published 13 February 2021

Academic Editor: Sang-Bing Tsai

Copyright (c) 2021 Hongming Wei. This is an open access article distributed under the Creative Commons Attribution License, which permits unrestricted use, distribution, and reproduction in any medium, provided the original work is properly cited.

\begin{abstract}
With the large-scale development of urban underground space, foundation pit engineering has become one of the important geotechnical engineering topics in urban construction. In this paper, the effects of foundation pit excavation and precipitation on adjacent buildings are studied in detail. The main research work includes the following aspects: summarizing and analyzing the soil consolidation theory, foundation pit excavation, and precipitation process; the influencing factors of the adjacent soil layer displacement; the influence mechanism and influence types of foundation pit excavation and precipitation on adjacent buildings. The finite element model considering the whole process of foundation pit excavation is established, and the variation law of the upper layer displacement around the foundation pit is analyzed. The deformation law of the retaining structure, the calculation results of precipitation and nonprecipitation, and different excavation methods will be analyzed and compared. The calculation results show that the displacement of the soil layer around the foundation pit is also different between different excavation methods. As the distance between the foundation pits increases, the lateral displacement of the underground continuous wall near the frame structure gradually decreases. The distance from the foundation pit wall is $30 \mathrm{~m}$. The maximum value of the lateral shift is reduced by $4.7 \%$ compared with $5 \mathrm{~m}$. The foundation pit is studied, as well as the law of internal force variation of adjacent buildings caused by digging and precipitation, and checking the safety and adaptability of structural members. The calculation results show that a large additional internal force will be generated on the bottom floor of the adjacent building, and some structural members will be damaged by the bearing capacity.
\end{abstract}

\section{Introduction}

The design and construction of deep foundation pit engineering have the characteristics of high technical content and strong comprehensiveness, which makes it difficult for some deep and even serious engineering accidents in some deep foundation pit excavation projects [1]. It is because the key technology is not designed and processed to create a tragedy, resulting in huge economic losses and serious social negative effects. It can be seen that with the gradual increase in the construction of deep foundation pits, the safety factor is gradually increasing, and the related deep foundation pit technology will be gradually improved through the study of some successful and failed deep foundation pit engineering, and in the experience of engineering practice, we should accumulate experience and continuously improve and promote the development of deep foundation pit construction technology and design theory.

Given the current emphasis on the construction industry, many domestic and foreign research teams have begun to impact settlement building in-depth study. Lin [2] used a bottom center column to distribute an excessive differential settlement of up to $75 \mathrm{~mm}$ to assess the stresses caused by excessive differential settlement in a typical tenstory reinforced concrete building. The analysis of damage and the resulting management of the built environment often requires high costs due to the establishment of reliable predictive models and the amount of data required to define the most appropriate repair work [3]. To understand the impact of forced migration and rural community resettlement on the very different built environment in urban environments, Billig [4] describes the process by which 
changes in the physical environment lead to major changes in the social fabric of the community and the cultural identity of community members. Xue [5] introduced the latest research results of ratcheting behavior of aluminum alloy 2124-T851 under uniaxial load to determine the effect of stress amplitude and average stress on material strain response. Nová?Ek [6] proposed different types of vertical shear analysis methods and their distribution and presented them on models with various levels of detail. Nan [7] not only ensures the safety of building construction and operation through settlement observation and analysis of settlement law but also provides reference and basis for the design and construction of similar high-rise buildings. Zana [8] used numerical simulation to determine the parameters that have the greatest impact on the shallow structural settlement and extended this analysis to determine the key parameters used to predict the residual tilt of the structure. Mirsayapov [9] used different calculation models to study the numerical calculation of foundation settlement of highrise buildings, including the improved Pasternak model based on the analysis of ground deformation map under three-axis state loading. Jin [10] studied the influence of the natural environment on the subsidence model through spatial and statistical analysis. Natural factors such as topography, rivers, and sunlight affect the construction of settlements at the regional and local levels. Li [11] in order to study the law of surface and upper surface settlement during foundation pit excavation, based on the theoretical analysis, combined with the on-site monitoring data of the Liuliuhu station in Shenyang, the numerical model of the surface settlement was proposed and analyzed.

Foundation pit excavation will cause uneven settlement on the surface of the pit, which will affect the normal use of adjacent buildings and even cause damage to adjacent buildings. At the same time, the adjacent buildings as overloading will cause the vertical and lateral deformation of the foundation pit to further increase, which may endanger the safety of the foundation pit excavation process. Therefore, the foundation pit interacts with adjacent buildings and interacts with each other. At present, there has been a lot of research and achievements on the surface deformation caused by the excavation of foundation pits at home and abroad. There are also some research results on the influence of surface deformation on adjacent buildings. However, there are few studies on the deformation of foundation pits and buildings under the joint action of foundation pit support structure, soil, and surrounding buildings.

In order to study the factors affecting the settlement of buildings, many research teams have carried out detailed analysis from various aspects and achieved good results. In order to study the influence of foundation pit excavation on the underground pipeline, Zhang established a three-dimensional model of the pipeline and foundation pit and analyzed the change law of pipeline deformation during the excavation process $[12,13]$. Jason Williams [14] incorporates hydrological data and ecohydrological relationships into ecological site descriptions (ESDs), based on resiliencebased strategic assessments and management of ecological state dynamics that affect national vulnerabilities, thereby improving sustainability education in assessing pastures and guiding the utility of resilience management strategies. Based on the monitoring data of the Shanghai Symphony Orchestra's foundation pit project and the operating tunnel and enclosure structure, Zhang analyzed the laws and characteristics of ground settlement around the project, deformation of the diaphragm, horizontal convergence, and vertical displacement of the foundation pit during different construction stages [15]. Jun [16] combined with the rare case of high-speed railway bridge piles around deep foundation pits, through finite element numerical simulation, analyzed the influence mode of deep foundation pit excavation on supporting structure and pile foundation and then verified the value with field monitoring data. Zhi-Guo [17] proposed a two-stage method to consider the viscoelasticity of soil to obtain the time domain solution of the interaction between adjacent piles and foundation pit excavation. The disturbed soil shows the rheological characteristics during excavation. Zhang [18] analyzed the existing tunnel deformation caused by different double foundation pit excavation in different construction stages by establishing a three-dimensional finite element model. The results show that when the double foundation pit is parallel to the adjacent tunnel, the tunnel deformation is larger, and the maximum horizontal displacement is about $10 \%$ larger than the displacement of the double foundation pit perpendicular to the tunnel. Later tunnels in later excavation will result in tunnel deformation greater than approximately $7 \%$ of previous excavations. Hailong [19] established a simulation model and compared it with the large finite element software ABAQUS with different mining schemes. The results show that in this case, the deformation of the supporting structure is the smallest and the safety of the foundation pit is the largest. That is, the slope $\mathrm{C}$ and the slope $\mathrm{S}$ are excavated to the shore line, and the deformation and stress of the retaining structure are stabilized and controlled. In order to study the soil pressure and deformation characteristics of double-row piles in foundation pit excavation, Yijun conducted large-scale physical model tests based on similar theoretical principles to simulate the deformation of doublerow piles in foundation pit excavation [20]. Hanson B retains all terms of the stress tensor and uses a Glen-type power law for viscosity calculations [21].

In this paper, the effects of foundation pit excavation and precipitation on adjacent buildings are studied in detail. The main research work includes the following aspects: summarizing and analyzing the soil consolidation theory, foundation pit excavation, and precipitation process; influencing factors of displacement in adjacent soil layers; influence mechanism and influence types of excavation and precipitation on adjacent buildings; analysis of internal force variation law of adjacent frame structures caused by the excavation of foundation pits; safety and adaptation of structural members. The finite element model considering the whole process of foundation pit excavation is established, and the variation law of the upper layer displacement around the foundation pit and the deformation law of the retaining structure are analyzed. The calculation results of precipitation and no consideration of precipitation and different 
excavation methods will be considered. Analyze and compare; study the law of internal force variation of adjacent buildings caused by foundation pit excavation and precipitation, and check the safety and adaptability of structural members.

\section{Method}

2.1. Mechanism and Type of Foundation Pit Excavation and Precipitation on Adjacent Buildings. The excavation and precipitation process of the foundation pit will cause the horizontal and vertical displacement of the soil around the foundation pit, and the vertical and horizontal displacements will change with the relative distance of the foundation pit and the depth of the soil layer. When the building is located around the foundation pit, the displacements caused by the deformation of the soil at different locations on the building are also different. At this time, additional stress and excessive vertical deformation or horizontal lateral displacement will be generated inside the building. When the additional stress reaches a certain value, the building will locally crack and may eventually cause local damage, tilt, or collapse of the structure.

2.1.1. Influence of Uniform Surface Settlement on Buildings. When the ground surface is uniformly settled, the building will sink as a whole. In general, this uniform settlement does not cause cracking and structural damage to the building. However, excessive surface subsidence will bring about adverse effects such as poor drainage on the ground and reduced space, which will affect its normal function.

\subsubsection{Influence of Uneven Surface Subsidence on Buildings.} Uneven settlement on the surface will cause excessive deformation, cracking, tilting, and even damage to the upper building. The uneven settlement response of the building to the foundation is more sensitive than uniform settlement. Due to the low rigidity of the brick-concrete structure, the wall is easily cracked under the uneven settlement of the foundation; the uneven settlement of the column foundation will generate large secondary stress in the frame structure, and the original force of the frame structure is changed. This case even affects the ductility and seismic frame structure; high-rise buildings with a high center of gravity easily lead to nonuniform overall tilt in building in-ground subsidence and affect the stability against overturning of the building.

\subsubsection{The Impact of Horizontal Movement on the Building.} The horizontal deformation of the surface has two kinds of stretching and compression, which has a great destructive effect on the building, especially the influence of tensile deformation. In the building in the stretching zone, the foundation bottom surface is subjected to the outward friction from the foundation, and the foundation side is subjected to the outward horizontal thrust from the foundation. However, the general building has little ability to resist the stretching, and the small building is small. Tensile deformation causes the building to crack.

\subsubsection{Building Cracking Caused by Changes in Surface} Curvature. When the local quality conditions are complex, the surface deformation is more complicated, and buildings with larger spans may be cracked due to changes in surface curvature. Under the action of negative curvature (the surface is relatively concave), the central part of the building is suspended, causing the wall to produce positive splayed cracks and horizontal cracks. If the length of the building is too large, the building will break from the bottom under the action of gravity, causing the building to break; under the action of the positive curvature (the surface is relatively convex), the two ends of the building will be partially suspended, so that the wall of the building has an inverted eight-word crack. In severe cases, the end of the beam will be pulled out from the wall or column, causing the building to collapse.

\subsection{Soil Seepage Consolidation Theory}

2.2.1. Groundwater Seepage Theory. The movement of groundwater is generally divided into the movement of saturated water with gravity water and the movement of capillary water with capillary water and combined water. The so-called groundwater movement refers to the movement of saturated water with gravity water. Seepage refers to the flow of groundwater in the pores of the soil. The seepage of groundwater is caused by the permeability of the soil medium and the head difference. When the groundwater is in a static equilibrium state, the water potential energy at each point in the soil is equal; when the groundwater level is lowered, the potential energy difference is generated at each point of the soil due to the destruction of the original balance of the soil from high energy to low energy. In the analysis of soil seepage, the head is often used to indicate potential energy, and the head $h$ at any point is as follows:

$$
h=z+\frac{u}{\gamma_{\omega}}+\frac{v_{x}^{2}}{2 g},
$$

where $z$ is the distance from the calculation point to the reference plane. $u$ is the pore water pressure at this point; $\gamma_{\omega}$ is the bulk density of water; $v_{x}$ is the seepage velocity. The three right items in the above equation represent the position head, the hole pressure head, and the speed head. Usually, due to the small flow velocity $v_{x}$ of the upper body, the influence on the total potential energy can be ignored, namely:

$$
h=z+\frac{u}{\gamma_{\omega}} .
$$

2.2.2. Biot Consolidation Theory. Take a microelement in the soil. If the volume force only considers gravity, the $z$-direction is opposite to the direction of gravity, and the 
compressive stress is positive. The three-dimensional equilibrium equation of the microelement is as follows:

$$
\left\{\begin{array}{l}
\frac{\partial \sigma_{x}}{\partial x}+\frac{\partial \tau_{y x}}{\partial y}+\frac{\partial \tau_{x x}}{\partial z}=0 \\
\frac{\partial \tau_{x y}}{\partial x}+\frac{\partial \sigma_{y}}{\partial y}+\frac{\partial \tau_{z y}}{\partial z}=0 \\
\frac{\partial \tau_{x}}{\partial x}+\frac{\partial \tau_{y z}}{\partial y}+\frac{\partial \sigma_{z}}{\partial z}=-\gamma
\end{array}\right.
$$

where $\gamma$ is the bulk density of the soil, and $\sigma_{x}, \sigma_{y}$, and $\sigma_{z}$ are the total stresses. According to the principle of effective stress, the total stress is the sum of the effective stress $\sigma^{\prime}$ and the pore water pressure $u$, and the pore water does not withstand the shear stress. The above formula can be rewritten as follows:

$$
\left\{\begin{array}{l}
\frac{\partial \sigma_{x}^{\prime}}{\partial x}+\frac{\partial \tau_{x x}}{\partial y}+\frac{\partial \tau_{z x}}{\partial z}+\frac{\partial u}{\partial x}=0 \\
\frac{\partial \tau_{x y}}{\partial x}+\frac{\partial \sigma_{y}^{\prime}}{\partial y}+\frac{\partial \tau_{z y}}{\partial z}+\frac{\partial u}{\partial y}=0 \\
\frac{\partial \tau_{x x}}{\partial x}+\frac{\partial \tau_{x a}}{\partial y}+\frac{\partial \sigma_{z}^{\prime}}{\partial z}+\frac{\partial u}{\partial z}=-\gamma
\end{array}\right.
$$

where $\sigma_{x}^{\prime}, \sigma_{y}^{\prime}, \sigma_{z}^{\prime}$ is the effective stress and $(\partial u / \partial x),(\partial u / \partial y)$, $(\partial u / \partial z)$ is the unit penetration force in each direction.

Under normal circumstances, it is assumed that the soil is completely saturated, the soil particles and water are incompressible, and the amount of water flowing out of the unit body during the $\mathrm{d} t$ time must be equal to the volume change of the unit body at the same time. When considering the source and sink term $\omega$, the continuous condition is as follows: the sum of the amount of water flowing out of the unit body and the change of the source and sink in the $\mathrm{d} t$ time must be equal to the volume change of the unit body in the same time, namely,

$$
\begin{aligned}
\frac{\partial}{\partial t}\left(\varepsilon_{v} \mathrm{~d} x \mathrm{~d} y \mathrm{~d} z\right)= & \frac{\partial\left(q_{x} \mathrm{~d} y \mathrm{~d} z\right)}{\partial x} d x+\frac{\partial\left(q_{y} \mathrm{~d} x \mathrm{~d} z\right)}{\partial y} d y \\
& +\frac{\partial\left(q_{z} \mathrm{~d} x \mathrm{~d} y\right)}{\partial z} \mathrm{~d} z+w \mathrm{~d} x \mathrm{dd} z .
\end{aligned}
$$

When the source sink term $\omega$ is not considered, the above formula is as follows:

$$
-\frac{\partial}{\partial t}\left(\frac{\partial w_{x}}{x}+\frac{\partial w_{y}}{y}+\frac{\partial w_{z}}{z}\right)+\frac{1}{\gamma_{\omega}}\left[\frac{\partial}{\partial x}\left(\kappa_{x} \frac{\partial u}{\partial x}\right)+\frac{\partial}{\partial y}\left(\kappa_{y} \frac{\partial u}{\partial y}\right)+\frac{\partial}{\partial z}\left(\kappa_{s} \frac{\partial u}{\partial z}\right)\right]=0
$$

The above formula is the continuous equation of seepage expressed by displacement and pore water pressure. The change of pore pressure and displacement at any point in the soil with time must satisfy both the equilibrium equation and the continuity equation. The two equations are related to Biot's consolidation equation. It contains 4 unknown functions $u, w_{x}, w_{y}, w_{z}$. The four unknowns can be solved under certain initial conditions and boundary conditions.

\subsection{Finite Element Method Application}

2.3.1. Discretization of the Model. The solution model is discretized into a finite number of cells, and the appropriate cell type is selected to simulate the actual physical properties. The cells are connected to each other only at the nodes; that is, the original solution domain is replaced by a set approximation of a finite number of cells.
2.3.2. Analysis of the Unit. Using the geometric equation, the strain relationship of the element is represented by the joint displacement:

$$
\{\varepsilon\}=[B]\{\delta\}^{e},
$$

where $\{\varepsilon\}$ is the element strain matrix and $[B]$ is the geometric matrix, while $\{\delta\}^{e}$ is the element displacement matrix.

Using the physical equation, the stress relationship of the element is represented by the joint displacement:

$$
\{\sigma\}=[D][B]\{\delta\}^{e} .
$$

$\{\sigma\}$ is the element stress matrix, and $[D]$ is the elastic matrix associated with the element material. The above formula is also applicable to nonlinear materials (such as nonlinear elasticity, elastoplasticity, viscoelasticity, etc.), and different material matrices $[D]$ are used for different materials. Using the principle of virtual work to establish the relationship between the joint force acting on the element 
and the displacement of the joint, i.e., the element stiffness equation:

$$
\{R\}^{e}=[k]\{\delta\}^{e},
$$

where $[k]$ is the element stiffness matrix.

2.3.3. Overall Analysis and Solution. According to the principle that adjacent units are equally displaced at the common node, each unit stiffness matrix is assembled to form an overall stiffness matrix; and the equivalent node force arrays acting on each unit are formed to form a total load array. The equilibrium equation of the whole structure expressed by the overall stiffness matrix $[K]$, the load array $[R]$, and the overall node displacement array $\{\delta\}$ is obtained:

$$
\{R\}=[K]\{\delta\} .
$$

After introducing the boundary conditions in the equations, the solution can be solved to obtain the unknown node displacement.

\section{Experiment}

\subsection{Observation Point Layout and Construction}

3.1.1. Level Reference Point. There are 3 reference points in this survey, numbered BM1-BM3, located in the northwest direction of the foundation pit, at the intersection of Zhongshan Road and Youth Street, 485 meters away from the northwest corner of the foundation pit, away from the construction deformation zone.

3.1.2. Settlement Observation Point. The ground subsidence observation point is set on the sidewalk isolation belt of the west side of the foundation pit and the sidewalk of the Daxi Road sidewalk on the south side. It is set at about 50 meters, and 11 ground settlement observation points are set up. The number is D1-D11. The ground settlement observation point is made of $\Phi 22 \mathrm{~m}$ and $1.5 \mathrm{~m}$ long steel bars.

3.1.3. Support Displacement Reference Point. In this measurement, four displacement reference points are set on the midpoint of the crown beam around the foundation pit, numbered G1-G4. The reference point is made of steel bars inserted into the center of the concrete platform and welded to the steel bars on the crown beam.

3.1.4. Displacement Observation Point. Support observation points are set on the crown beam of the cast-in-place piles around the foundation pit. The distance between the observation points is about 40 meters, and there are 13 points, numbered B1-B13. The observation points are welded by the steel bars in the crown beam, and the bottom of the reinforcement is cemented to ensure that each measurement point is firmly integrated with the crown beam.

\subsection{Evaluation Criteria}

(1) "National Standards of the People's Republic of China and Engineering Measurement Standards (GB50026-93)"

(2) "National Standards of the People's Republic of China and Building Foundation Design Codes (GB50007-2002)"

(3) "Industrial Standards of the People's Republic of China.Technical Regulations for Building Foundation Pit Support (JGJ120-99)"

(4) "Industrial Standards of the People's Republic of China and Technical Specifications for Building Foundation Pit (YB9258-97)"

Both the elevation and the plane use an independent coordinate system. The error in the elevation of the vertical displacement observation point is $\pm 1.0 \mathrm{~mm}$, and the error in the position of the horizontal displacement observation point is $\pm 3.0 \mathrm{~mm}$. According to the national second-class leveling technical requirements, the data can reflect the real situation.

3.3. Monitoring Instruments and Accuracy. The settlement observation instrument adopts the Swiss N3 precision level instrument (which is a DS05 class instrument) and an indium steel ruler. Level accuracy: $\pm 0.4 \mathrm{~mm} / \mathrm{km}$.

The displacement observation instrument adopts Japan Topcon GTS-332 W total station instrument, ranging accuracy: $\pm 2 \mathrm{~mm}+2 \mathrm{ppm}$; angle measurement accuracy: $2^{\prime \prime}$.

\section{Results and Discussions}

\subsection{Settlement Analysis of Adjacent Frame Structure of Foundation Pit}

4.1.1. Influence of Frame Structure Distance from Foundation Pit. When the distance between the adjacent frame structure and the foundation pit wall is $5 \mathrm{~m}, 10 \mathrm{~m}, 15 \mathrm{~m}, 20 \mathrm{~m}$, $30 \mathrm{~m}$, respectively, the foundation settlement is shown in Figure 1.

As can be seen from Figure 1, the settlement at the same soil layer position considering the frame structure is larger than that without considering the building, compared to the case where the building is not considered. It can be seen from Figure 1 that under different distances, the settlement trend of the adjacent frame structure foundation is basically the same, the foundation settlement near the foundation pit is larger than the settlement on the other side of the foundation, and the maximum settlement occurs when the distance from the foundation pit is $10 \mathrm{~m}$. Time: It can be seen from Table 1 that when the distance $D$ of the frame structure from the foundation pit wall is $5 \mathrm{~m}, 10 \mathrm{~m}$, $15 \mathrm{~m}, 20 \mathrm{~m}, 30 \mathrm{~m}$, respectively, the maximum difference $\Delta \delta_{v m}$ of settlement differences between adjacent columns is $6.84 \mathrm{~mm}$, $6.96 \mathrm{~mm}, 6.34 \mathrm{~mm}, 5.14 \mathrm{~mm}$, and $2.99 \mathrm{~mm}$, respectively. Under different distances, the maximum value of settlement difference $\Delta \delta_{v m}$ between adjacent columns occurs when the distance between the frame structure and the foundation pit is $10 \mathrm{~m}$, which is about 2.3 times the distance from the foundation pit of 


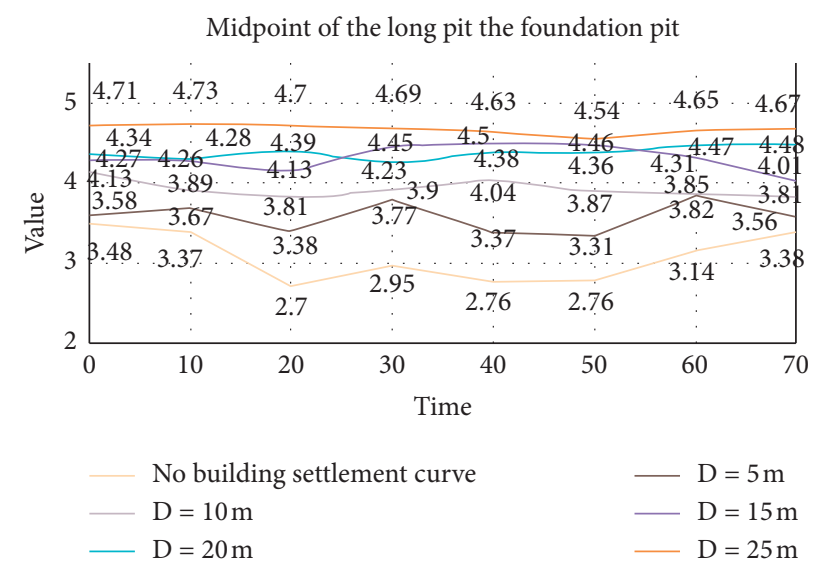

FIgURE 1: Settlement diagram of frame structure foundation at different distances from the foundation pit wall.

TABLE 1: Settlement difference of adjacent column bases at different distances from the foundation pit wall.

\begin{tabular}{|c|c|c|c|c|c|}
\hline \multirow[t]{2}{*}{ Analysis item } & \multicolumn{5}{|c|}{ Distance from the foundation pit wall } \\
\hline & 5 & 10 & 15 & 20 & 25 \\
\hline \multirow{5}{*}{ Settlement difference between adjacent columns } & 1.18 & 2.94 & 4.47 & 3.94 & 2.33 \\
\hline & 3.95 & 6.33 & 6.34 & 5.14 & 2.99 \\
\hline & 6.61 & 6.96 & 6.07 & 4.74 & 2.64 \\
\hline & 6.84 & 6.39 & 5.28 & 4.06 & 2.21 \\
\hline & 6.81 & 6.38 & 5.33 & 4.14 & 2.25 \\
\hline
\end{tabular}

$30 \mathrm{~m}$. In addition, according to the "Code for Design of Building Foundations," the allowable difference of settlement of adjacent columns of the frame structure is $0.002 \mathrm{~L}$, and $L$ is the center and distance of adjacent columns. As can be seen from Figure 1, the center distance of the adjacent column base is $6 \mathrm{~m}$, and the allowable value of the difference in the settlement is $12 \mathrm{~mm}$. It can be seen from Table 1 that the maximum settlement difference between adjacent column bases is less than the specification limit.

\subsubsection{Frame Structure Foundation Settlement Results.} During the foundation pit excavation process, when the excavation depth $\mathrm{H}$ of the foundation pit is $3 \mathrm{~m}, 7 \mathrm{~m}$, and $10 \mathrm{~m}$, respectively, the settlement of the adjacent frame structure foundation is shown in Figure 2.

It can be seen from Figure 2 that under different excavation depths, the settlement trend of the foundation adjacent to the frame structure is consistent, and the settlement of the foundation near the foundation pit is larger than the settlement of the other side of the foundation. It can be seen from Figure 2 that as the excavation depth increases, the settlement of the frame structure foundation gradually increases, and the maximum settlement increases from $17.89 \mathrm{~mm}$ to $38.55 \mathrm{~mm}$. When the excavation depth is $10 \mathrm{~m}$, the maximum settlement $\Delta \delta_{v m}$ is about Dig depth 2.2 times the depth of $3 \mathrm{~m}$.

\subsection{Internal Force Analysis of Adjacent Frame Shear Structure of Foundation Pit}

4.2.1. The Law of Internal Force Variation of the Adjacent Frame Shear Wall Structure of the Foundation Pit. In order to make the influence of the foundation pit excavation process on the adjacent frame shear structure as large as possible, the distance $D$ of the frame shear structure from the foundation pit wall is $10 \mathrm{~m}$, the depth of the underground continuous wall into the soil layer Dw is $25 \mathrm{~m}$, and the thickness of the underground continuous wall is $600 \mathrm{~mm}$, and the settlement diagram of the frame shear structure is shown in Figure 3.

According to the calculation in Figure 3, the settlement difference $\Delta \delta_{v}$ at both ends of the foundation is $104.6 \mathrm{~mm}$, and the foundation inclination values are all 0.00349 , which is greater than the limit of 0.003 for the Design Standard for Building Foundations.

\subsubsection{Checking Calculation of Bearing Capacity of Frame} Beam. The bottom layer frame beam with the largest bending moment is selected to check the bending bearing capacity. It can be seen that the maximum bending moment of the beam end is $M 1=35.52 \mathrm{kN} / \mathrm{m}$. In addition, according to the calculation results of PKPM internal force, the beam end moment of the frame beam under the dead load and live load is $M 2=69.2 \mathrm{kN} / \mathrm{m}$, and the total bending moment value of the beam end is $M=M 1+M 2=104.72 \mathrm{kN} / \mathrm{m}$. The frame beam has a cross section of $\mathrm{bxh}=200 \mathrm{~mm} \times 600 \mathrm{~mm}$ and is made of C30 concrete and HRB335 steel. Calculated by the formula, the beam end bearing capacity $M$ is $97.78 \mathrm{kN} / \mathrm{m}$, which is less than the design value of $104.72 \mathrm{kN} / \mathrm{m}$. That is, the frame beam will be deformed by the normal section.

4.3. Settlement Analysis of Adjacent Frame Shear Wall Structure in Foundation Pit. During the foundation pit excavation process, when the excavation depth $\mathrm{H}$ of the 


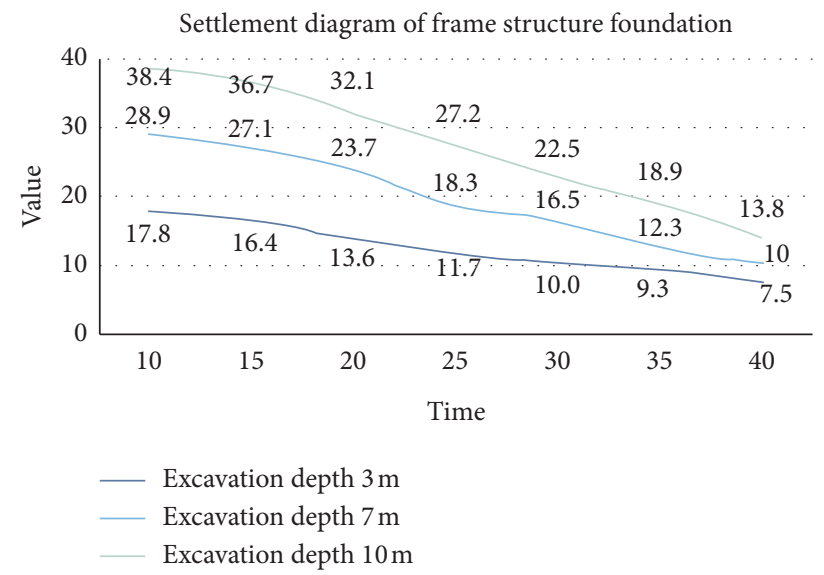

Figure 2: Settlement diagram of frame structure foundation under different excavation depth.

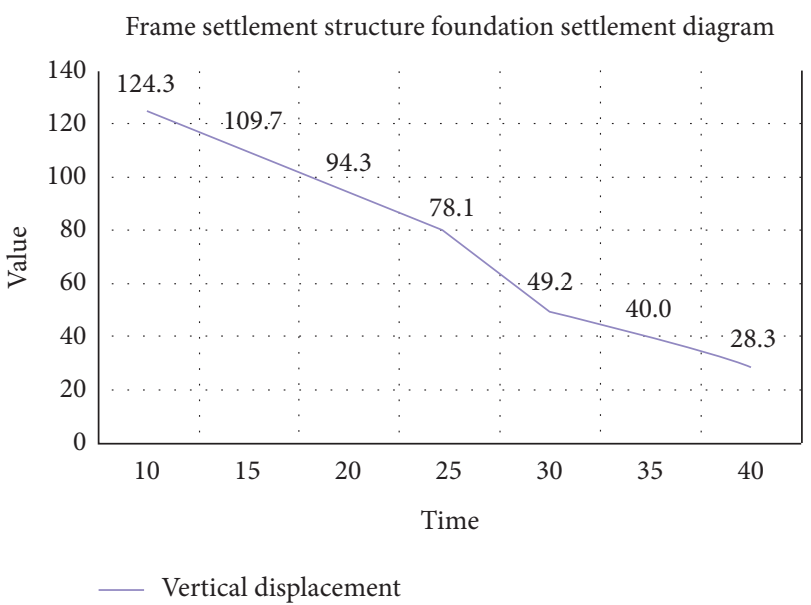

FIgURE 3: Frame settlement structure foundation settlement diagram.

foundation pit is $3 \mathrm{~m}, 7 \mathrm{~m}$, and $10 \mathrm{~m}$, respectively, the settlement of the adjacent frame shear structure foundation is shown in Figure 4.

As can be seen from Figure 4, under different excavation depths, the settlement trend of the foundation adjacent to the frame shear structure is consistent, and the settlement of the foundation near the foundation pit is larger than the settlement on the other side of the foundation. With the increase of excavation depth, the settlement of the frame shear structure foundation is gradually enlarged. The maximum settlement $\Delta \delta_{v m}$ is gradually increased from $19.03 \mathrm{~mm}$ to $46.41 \mathrm{~mm}$, and the excavation depth is about 2.4 times the excavation depth of $3 \mathrm{~m}$. Under different excavation depths, when the excavation depth is $10 \mathrm{~m}$, the average settlement of the frame shear structure foundation and the settlement difference between the two ends are the largest. The maximum settlement $\Delta \delta_{v m}$ of the excavation depth of $10 \mathrm{~m}$ is about 2.9 of the excavation depth of $3 \mathrm{~m}$. The maximum value $\Delta \delta_{v m}$ of the average settlement under

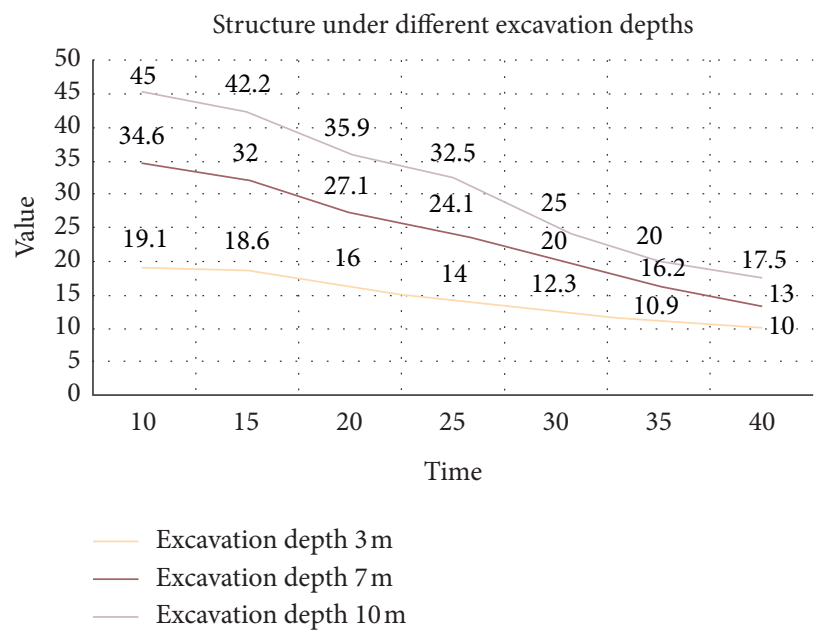

FIgURE 4: Foundation settlement diagram of the frame shear structure under different excavation depths.

different excavation depths is $30.07 \mathrm{~mm}$, which is less than the allowable value of $200 \mathrm{~mm}$; the basic inclination maximum $\theta_{f m}$ is 0.0011 , which is less than the allowable value of 0.003 .

\section{Conclusions}

In this paper, a finite element model of foundation pit excavation considering adjacent frame structure is established, and the distance from the foundation pit, foundation type, excavation depth, precipitation, thickness, the depth of the retaining structure, and excavation are analyzed based on the finite element model. Modes and other factors affect the settlement of the foundation structure adjacent to the foundation pit and the deformation of the retaining structure. At the same time, the variation law of internal force caused by the excavation of the foundation pit is analyzed, and the safety and adaptability of the structural 
members are checked. This paper makes full use of the combination of theoretical research and empirical research and makes an empirical analysis based on the actual situation. According to the results of finite element analysis, the following conclusions can be drawn:

(1) After comparison and analysis, the distance $D$ between the adjacent frame structure and the foundation pit wall is $5 \mu \mathrm{m}, 10 \mu \mathrm{m}, 15 \mu \mathrm{m}, 20 \mu \mathrm{m}, 30 \mu \mathrm{m}$, respectively. It can be found that the settlement maximum value $\delta_{v m}$ and the settlement difference between adjacent column bases under different distances. The maximum value $\delta_{v m}$ occurs when the distance between the frame structure and the foundation pit is $10 \mathrm{~m}$, and the maximum value of the settlement difference $\delta_{v m}$ when the distance from the foundation pit is $10 \mathrm{~m}$ is about 2.3 times the distance from the foundation pit of $30 \mathrm{~m}$. In addition, as the distance between the frame structure and the foundation pit increases, the lateral displacement of the underground continuous wall near the frame structure side gradually decreases, and the distance from the foundation pit wall is $30 \mathrm{~m}$. The lateral shift maximum value is reduced by 4.7 compared with $5 \mathrm{~m} . \%$.

(2) Comparative analysis: the excavation depth $\mathrm{H}$ of the foundation pit is $3 \mathrm{~m}, 7 \mathrm{~m}, 10 \mathrm{~m}$, respectively. It can be found that with the increase of the excavation depth, the settlement and settlement difference of the frame structure foundation are gradually increased, and the excavation depth is $10 \mathrm{~m}$. The maximum settlement $\delta_{v m}$ of the settlement difference is about 2.8 times the excavation depth of $3 \mathrm{~m}$. In addition, with the increase of excavation depth, the maximum value of lateral displacement of underground continuous wall is gradually increased, and the maximum value of lateral displacement $\Delta \delta_{\text {wrm }}$ is about 3.7 times of excavation depth of $3 \mathrm{~m}$ when excavation depth is $10 \mathrm{~m}$.

(3) Comparative analysis: the situation of using one precipitation, two precipitations, and three precipitations in the excavation process of the foundation pit can be found that with the increase of the number of precipitations during the excavation process, the settlement and settlement difference of the foundation are gradually reduced. The maximum settlement of the foundation and the maximum difference $\Delta \delta_{v m}$ of the settlement difference in single precipitation are about 1.2 times that of the three precipitations. In addition, with the increase of the number of precipitations, the maximum lateral displacement of the underground continuous wall and the lateral displacement at the top of the wall have a decreasing trend. The maximum value $\Delta \delta_{v m}$ of the lateral displacement of the underground continuous wall during the three precipitations is reduced compared to the one precipitation $11.5 \%$.

\section{Data Availability}

No data were used to support this study.

\section{Conflicts of Interest}

The author declares no conflicts of interest.

\section{References}

[1] B. S. Murugan, M. Elhoseny, K. Shankar, and J. Uthayakumar, "Region-based scalable smart system for anomaly detection in pedestrian walkways," Computers \& Electrical Engineering, vol. 75, pp. 146-160, 2019.

[2] L. Lin, A. Hanna, A. Sinha, and L. Tirca, "High-rise building subjected to excessive settlement of its foundation: a case study," International Journal of Structural Integrity, vol. 8, no. 2, pp. 210-221, 2017.

[3] D. Peduto, G. Nicodemo, J. Maccabiani, and S. Ferlisi, "Multiscale analysis of settlement-induced building damage using damage surveys and DInSAR data: a case study in The Netherlands," Engineering Geology, vol. 218, pp. 117-133, 2017.

[4] M. Billig, "Effects of the forced resettlement of a community from an agricultural settlement to a high-rise building," GeoJournal, vol. 81, no. 1, pp. 123-137, 2016.

[5] L. Xue, "Prediction algorithm for settlement amplitude of Taizhou's building foundation," Journal of Discrete Mathematical Sciences and Cryptography, vol. 21, no. 2, pp. 233-237, 2018.

[6] J. Nová?ek, Z. Miloš, "Contribution of settlement of a highrise building with recession in a ground plan to punching shear," Solid State Phenomena, vol. 259, pp. 198-202, 2017.

[7] W. Nan and Z. Yu, "Settlement observation method of super high-rise building," Journal of Geomatics, vol. 42, no. 3, pp. 110-112, 2017.

[8] K. Zana, D. Shideh, B. Zach et al., "Key predictors of structure settlement on liquefiable ground: a numerical parametric study," Soil Dynamics and Earthquake Engineering, vol. 113, pp. 286-308, 2018.

[9] I. Mirsayapov and I. Koroleva, "Long-term settlements assessment of high-rise building groundbase based on analytical ground deformation diagram," Procedia Engineering, vol. 165, pp. 519-527, 2016.

[10] T. Jin, H. Chen, and D. Xiao, "Influences of the natural environment on traditional settlement patterns: a case study of Hakka traditional settlements in eastern guangdong province," Journal of Asian Architecture \& Building Engineering, vol. 16, no. 1, pp. 9-14, 2017.

[11] Y. Li, C. Wang, Q. Sun et al., "Influence of subway deep foundation excavation on surrounding ground settlement," Journal of Liaoning Technical University, vol. 36, no. 4, pp. 387-390, 2017.

[12] J. Zhang, R. Xie, and H. Zhang, "Mechanical response analysis of the buried pipeline due to adjacent foundation pit excavation," Tunnelling and Underground Space Technology, vol. 78, pp. 135-145, 2018.

[13] C. Jason Williams, F. B. Pierson, K. E. Spaeth et al., "Incorporating hydrologic data and ecohydrologic relationships into ecological site descriptions," Rangeland Ecology \& Management, vol. 69, no. 1, pp. 4-19, 2016.

[14] X. Zhang, Y. Zhang, Z. Liu, and J. Liu, "Analysis of heat transfer and flow characteristics in typical cambered ducts," International Journal of Thermal Sciences, vol. 150, Article ID 106226, 2020.

[15] Z. Zhang, Q. Bai, Y. Jiang et al., "In-situ monitoring analyses of the influences of deep foundation pit excavation on 
adjacent metro tunnels and surrounding strata," Modern Tunnelling Technology, vol. 54, no. 2, pp. 177-184, 2017.

[16] H. U. Jun, "Research on the influence of excavation of deep foundation pit to adjacent existing high-speed railway bridge pile foundations stability," Journal of Railway Engineering Society, vol. 34, no. 6, pp. 12-17, 2017.

[17] Z. Zhi-Guo, L. U. Ming-Hao, and G. Jian-Fei, “Time-domain solution for influence of excavation on adjacent pile deformation in visco-elastic foundation," Rock \& Soil Mechanics, vol. 38, no. 10, pp. 3017-3028, 2017.

[18] Z. Zhang, S. Fei, L. Xing et al., "Analysis on the influence of adjacent double foundation pit excavation on tunnel deformations," Journal of University of Shanghai for Science \& Technology, vol. 39, no. 2, pp. 176-181, 2017.

[19] W. Hailong, F. Tao, Y. U. Xiaoqiang et al., "The excavation scheme optimization of beside river interchange ramp unsymmetrical loaded foundation pit," Journal of Railway Science \& Engineering, vol. 60, no. 2, pp. 64-66, 2016.

[20] Z. Yijun, Y. Aijun, L. Haobo et al., "Correction of earth pressure and analysis of deformation for double-row piles in foundation excavation in changchun of China," Advances in Materials Science and Engineering, vol. 2016, pp. 1-10, 2016.

[21] B. Hanson, "A fully three-dimensional finite-element model applied to velocities on Storglaciären, Sweden," Journal of Glaciology, vol. 41, no. 137, pp. 91-102, 2017. 